\title{
ANTICORPOS ANTI-Leptospira spp. E LEPTOSPIRÚRIA EM GATOS NA REGIÃO METROPOLITANA DE CURITIBA/PR-BRASIL
}

\author{
(Anti-Leptospira spp. antibodies and leptospiruria in cats in the metropolitan area of \\ Curitiba, State of Paraná - Brazil) \\ Carolina Trochmann Cordeiro ${ }^{1}$, Rafael Felipe da Costa Vieira ${ }^{1}$, Simone Tostes de Oliveira ${ }^{1}$ \\ 1Programa de Pós-Graduação em Ciências Veterinárias. Setor de Ciências Agrárias. Universidade Federal do Paraná. \\ ${ }^{*}$ Correspondência: tostesimone@gmail.com
}

RESUMO: A leptospirose ainda é pouco elucidada em gatos e o papel da espécie na epidemiologia da doença é indeterminado. Os dados sobre a doença clínica nos mesmos são raros, no entanto, a resposta com anticorpos específicos após infecção é comprovada e apresenta valores de prevalência variando de 5,6 a 33\%. Apesar da maior resistência da espécie, não se deve ignorar a possibilidade de transmissão, pois é comprovado que após infecção ou doença pode ocorrer eliminação do patógeno na urina. Neste estudo objetivou-se detectar leptospirúria por reação em cadeia da polimerase (PCR) e anticorpos contra L. interrogans com o uso de soroaglutinação microscópica (SAM) em gatos expostos a fatores associados a infecção na região metropolitana de Curitiba/PR. Foram coletadas amostras de sangue e urina de 65 gatos (13 de São José dos Pinhais e 52 de Pinhais), no período de agosto a novembro de 2016 . Ao todo, três animais $(4,6 \%)$ foram soropositivos para o sorovar Pomona, com títulos variando de 200 a 400. Das 65 amostras de urina, uma $(1,53 \%)$ foi positiva na PCR. Sendo assim, podemos concluir que gatos da região metropolitana de Curitiba/PR expostos a fatores associados a infecção estão sucetíveis a se contaminarem com Leptospira spp. e podem apresentar leptospirúria.

Palavras-chave: felinos; leptospirose; saúde pública; sorologia; zoonose

ABSTRACT: Leptospirosis is still poorly known in cats and the role of the specie in the disease epidemiology is indeterminate. Clinical disease descriptions are rare, although cats may produce response with specific antibodies after infection. Serological studies have showed a varying prevalence from 6.96 to $26.7 \%$. Despite the specie's larger resistance, the transmission possibility should not be ignored since is confirmed that after infection or disease the pathogen can be eliminated in the urine. The study's objective was to detect leptospiruria by polymerase chain reaction (PCR) and anti-Leptospira spp. Antibodies by microscopic agglutination test (MAT) in cats exposed to infection association factors in the metropolitan zone of Curitiba / PR. Blood and urine samples were collected from 65 cats (13 from São José dos Pinhais and 52 from Pinhais) from august to november 2016(th). Three animals $(4.6 \%)$ were seropositive for the Pomona serovar, with titles ranging from 200 to 400 . Of all the 65 samples collected, one (1.53\%) was PCR positive. As a result, we can conclude that cats from the metropolitan area of Curitiba/PR exposed to infection associated factors are susceptible to contamination with Leptospira spp. and may show leptospiruria.

Key Words: cat; leptospirosis; public health; serology; zoonosis 


\section{INTRODUÇÃO}

A leptospirose é um problema de saúde pública de importância mundial e afeta grande parte dos mamíferos, incluindo o homem (Bharti et al., 2003). É considerada uma doença sistêmica em seres humanos e em diversos animais, com uma quantidade variada de sinais, dentre eles: febre, insuficiência renal e hepática, alterações pulmonares e alterações reprodutivas. Muitos casos podem ser subclínicos e geralmente associados a sorovares adaptados aos hospedeiros (AndréFontaine, 2006). Após recuperação da doença clínica alguns animais podem tornar-se portadores assintomáticos, e contaminarem o ambiente por longos períodos com eliminação de leptospiras pela urina (Adler e Moctezuma, 2010). A grande quantidade de espécies capazes de albergar e eliminar a bactéria assegura a persistência do agente no ambiente e também o elevado potencial de infecção (Markovich et al., 2012).

Por muito tempo acreditouse que os gatos possuíam resistência à infecção, produção de doença clínica ou resposta com anticorpos específicos. No entanto, estudos sorológicos demonstram valores de prevalência variando de 5,6 a $33 \%$ e diversos sorogrupos são relatados. Há também relato de sinais clínicos de poliúria e polidpsia entre os animais positivos (Lévesque et al., 1995; Agunloye e Nash, 1996; Millán et al., 2009; Lapointe et al., 2013). Em um relato de caso, a clínica do paciente foi comparada a clínica subaguda do cão com leptospirose (Beaudu-Lange e Lange, 2014).

Os felinos são cada vez mais frequentes nos domicílios e geralmente possuem estreita relação humano-animal, fatos que corroboram para um possível aumento no risco de ocorrência de zoonoses no núcleo familiar, principalmente em animais portadores assintomáticos. Apesar da maior resistência da espécie, não se deve ignorar a possibilidade de transmissão, pois é comprovado que após infecção ou doença pode ocorrer eliminação do patógeno na urina (Arbour et al., 2012; Fenimore et al., 2012; Chan et al., 2014; Rodriguez et al., 2014; Pol, 2016). Ainda não há informações sobre a ocorrência de leptospiras em gatos na região metropolitana de Curitiba/PR. Neste estudo objetivou-se detectar leptospirúria por reação em cadeia da polimerase (PCR) e anticorpos contra L. interrogans com $O$ uso de soroaglutinação microscópica (SAM) em gatos expostos a fatores associados à infecção.

\section{MATERIAL E METODOS}

\section{Animais}

Gatos provenientes de campanhas de castração realizadas em associação do Hospital Veterinário da UFPR com os municípios de Pinhais e São José dos Pinhais, no período de agosto a novembro de 2016. Os critérios de inclusão e fatores associados à infecção foram: "livre acesso à rua" ou "período de vida livre" e/ou "contato prévio com roedores". E como critério de exclusão "tratamento há menos de 3 meses com doxiciclina". Esses critérios foram determinados com base em revisão bibliográfica feita sobre 0 assunto.

\section{Questionários}

Com o objetivo de avaliar fatores associados a infecção e possíveis sinais clínicos, foram aplicados questionários aos responsáveis pelos animais. As informações obtidas foram: idade, gênero, tratamentos realizados há menos de 1 ano, histórico clínico, sinais clínicos atuais, número de contactantes, 
histórico de resgate ou adoção, acesso livre a área externa, contato com roedores, hábito de caça em geral, contato com animais silvestres ou de produção, saneamento básico na região da habitação e risco de alagamento ou presença de rios. Os responsáveis também assinaram termo de consentimento para participação na pesquisa.

\section{Amostras}

Como os animais já seriam anestesiados para 0 procedimento cirúrgico de castração, as amostras de sangue e urina foram coletadas somente após sedação, com o intuito de evitar estresse pela contenção e manejo desnecessário. A amostra de sangue (1 a $2 \mathrm{~mL}$ ) foi coletada da veia jugular $e$ armazenada em tubos sem anticoagulante. Foi posteriormente centrifugada a $600 \mathrm{rpm}$ por 15 minutos para obtenção do soro. O soro foi separado e armazenado à temperatura de $-20^{\circ} \mathrm{C}$ para posterior análise sorológica.

As amostras de urina foram coletadas por cistocentese (2 a $10 \mathrm{~mL}$ ). Imediatamente após a coleta, a urina foi fracionada em duas alíquotas, sendo a primeira armazenada em tubo falcon com adição imediata de tampão fosfato salino (PBS) na proporção de 1 PBS: 2,5 urina (v/v) com objetivo de neutralização da mesma para posterior extração de DNA. A segunda alíquota foi armazenada em tubo coletor universal para posterior refratometria e análise química (Tira reagente de urinálise ComburTestRoche®). As amostras foram mantidas refrigeradas a $4^{\circ} \mathrm{C}$ até os processos de extração e urinálise (máximo 4 horas).

\section{Sorologia (SAM)}

Os soros foram encaminhados ao Centro de Diagnóstico Marcos Enrietti para a realização do método de soroaglutinação microscópica (SAM).
Foram consideradas positivas as amostras com títulos maiores ou iguais a 100. Os sorovares testados foram: Autumnalis, Bratislava, Canicola, Castellonis, Copenhageni, Cypnopteri, Grippotyphosa, Hardjo, Icterohaemorrhagiae, Pomona e Pyrogenes.

Previamente aos testes, os antígenos foram examinados ao microscópio de campo escuro com o objetivo de verificar a sua mobilidade, a presença de auto aglutinação ou de contaminantes. Os soros foram triados na diluição de 1:50, e aqueles que apresentaram $50 \%$ ou mais de aglutinação foram titulados com uma série de diluições geométricas de razão dois. O título do soro foi a recíproca da maior diluição que apresentou resultado positivo.

\section{Extração de DNA}

Para a extração de DNA das amostras de urina foi utilizado um protocolo modificado (Lucchesi et al., 2004). O mesmo foi previamente testado com urina de gato sabidamente negativa e contaminação com quantidades conhecidas de Leptospira spp. nas concentrações de $10^{5}$ até $10^{2}$ leptospiras $/ \mathrm{mL}$ de urina. A sensibilidade do procedimento foi de $10^{4}$ leptospiras $/ \mathrm{mL}$ ou 5 cópias/reação com extrações realizadas até 4 horas após coleta e contaminação.

As amostras de urina, previamente neutralizadas com PBS, foram fracionadas em duas alíquotas de $1,5 \mathrm{~mL}$ e então passaram por incubação a $37^{\circ} \mathrm{C}$ durante 10 minutos. Foi então realizada centrifugação a $3000 \mathrm{rpm}$ durante 15 minutos, os sobrenadantes de cada amostra foram preservados e foram desprezados os pellets formados. Os sobrenadantes foram então centrifugados a $13000 \mathrm{rpm}$ durante 20 minutos, após isso foram descartados os sobrenadantes e preservados os pellets. Foi adicionado $1 \mathrm{~mL}$ de PBS a 
cada alíquota com a devida homogeneização, e feita nova centrifugação a 13000 rpm com duração de 20 minutos. Novamente foram descartados os sobrenadantes e preservados os pellets com nova diluição com PBS na quantidade de 100 $\mu \mathrm{l}$. As amostras foram incubadas a $94^{\circ} \mathrm{C}$ durante 10 minutos $\mathrm{e}$ ao fim do processo foram armazenadas a $-20^{\circ} \mathrm{C}$ para posterior análise molecular.

\section{PCR}

Os primers usados foram: LIPL3245Fw (5'-AAG CAT TAC CGC TTG TGG TG-3') e LIPL32286Rv (5'GAA CTC CCA TTT CAG CGA TT-3') dirigidos ao gene LipL32 (242pb). A reação de $P C R$ foi realizada com uma mistura total de reação de $25 \mu \mathrm{l}$ contendo: $5 \mu \mathrm{l}$ da amostra, 1x PCR buffer (Invitrogen, Life Technologies, São Paulo, Brasil), 1,5 mM de $\mathrm{MgCl}_{2}$, $0,2 \mu \mathrm{M}$ de cada desoxinucleotídeo trifosfato (dATP, DCTP, dGTP, dTTP), $1,0 \cup$ de Taq DNA polimerase (Recombinant $\AA$ Taq DNA Polymerase, Invitrogen) e 0,2 $\mu \mathrm{M}$ de cada primer.

A PCR foi realizada utilizando o termociclador (SimpliAmp TM Thermal Cycler, Applied Biosystems, Califórnia, EUA). O protocolo de amplificação consistiu em 3 minutos a $94^{\circ} \mathrm{C}$ para desnaturação inicial, 35 ciclos de amplificação (desnaturação a $94^{\circ} \mathrm{C}$ durante 45 segundos, anelamento a $52^{\circ} \mathrm{C}$ durante 45 segundos e extensão a $72^{\circ} \mathrm{C}$ durante 45 segundos) e extensão final de 5 minutos a $72^{\circ} \mathrm{C}$. Cada reação incluiu um controle negativo (água ultrapura), controle negativo da extração de DNA e um controle positivo (DNA extraído de culturas de leptospiras). Os produtos foram submetidos a eletroforese em gel de agarose a 1,5\% durante 1 hora a $100 \mathrm{~V}$, seguido por coloração com brometo de etídio $(0,5$ $\mu \mathrm{g} / \mathrm{mL}$ de tampão TBE). A visualização e a fotografia das bandas dos produtos de tamanho esperado foram realizadas sob luz ultravioleta (L-PIX-HE®, Loccus Biotecnologia, São Paulo, Brasil) utilizando o software L-PIX-IMAGE® (Loccus Biotecnologia, São Paulo, Brasil).

\section{Sensibilidade dos primers}

Foi utilizada uma cultura fresca de Leptospira interrogans s. Canicola para criar uma diluição seriada de $1 \times 10^{8}$ até $1 \times 10^{1}$ leptospiras $/ \mathrm{mL}$ em solução estéril de PBS. O DNA dessas amostras foi extraído com a incubação das mesmas por 10 minutos a $94^{\circ} \mathrm{C}$ e a PCR foi realizada seguindo as mesmas condições das demais amostras. O par de primers mostrou sensibilidade de reconhecer até $1 \times 10^{3}$ leptospiras $/ \mathrm{mL}$ ou 5 copias/reação.

\section{RESULTADOS E DISCUSSÃO}

Foram avaliados, no total, 65 gatos, sendo 3 (4,6\%) soropositivos (Tabela 1). Dos 52 gatos (27 machos e 25 fêmeas) examinados provenientes do município de Pinhais, um $(1,9 \%)$ foi soropositivo para a o sorovar Pomona com título 100. No município de São José dos Pinhais, dos 13 animais coletados (6 machos e 7 fêmeas), dois $(15,4 \%)$ foram positivos para o sorovar Pomona com títulos 200 e 400. Outros estudos em gatos também demonstram títulos de anticorpos baixos, variando de 100 até 400 (Lapointe et al., 2013; Azócar-Aedo et al., 2014; Brasil et al., 2014; Chan et al., 2014; Rodriguez et al., 2014; Garoussi et al., 2015). A razão para os valores baixos permanece desconhecida, alguns autores sugerem que isso possa ocorrer por uma resposta imune rápida, seguida de rápido declínio no título (Shophet e Marshall, 1980) ou pela necessidade de baixos títulos de anticorpos para controlar a infecção (Rodriguez et al., 2014). Há ainda a hipótese de que os sorovares que afetam os gatos podem não ser descritos até o momento ou 
serem diferentes dos habitualmente testados para cães e humanos, sendo assim, a prevalência dos estudos estaria correlacionada a reações cruzadas entre os sorovares (Markovich et al., 2012).

O sorovar Pomona encontrado nos três animais positivos foi relatado também como o mais comum em alguns estudos em gatos, como em Patos, PB/Brasil (Brasil et al., 2014), em Montreal/Canadá (Rodriguez et al., 2014) e no relato de 3 casos clínicos de leptospirose em gatos também em Montreal/Canadá (Arbour et al., 2012). É também um dos três sorovares mais comuns em outros estudos sorológicos em gatos (Jamshidi et al., 2009; Sonja et al., 2014; Garoussi et al., 2015). Esse sorovar é geralmente encontrado em suínos, considerados reservatórios primários do mesmo (Faine et al., 1999). No entanto, no presente estudo, nas análises feitas com 0 uso dos questionários não foi relatado nenhum contato dos gatos positivos com essa espécie animal. Sendo assim, esse achado pode representar reações cruzadas com outros sorovares não testados ou contato direto ou indireto com alguma outra espécie animal.

Com base nos questionários dos três animais os possíveis fatores associados a infecção podem ser: hábito de caça geral, contato com roedores, acesso à rua e coabitar com outros gatos e cães. Um dos animais possuía outros possíveis fatores associados a infecção, tais como: contato com animais silvestres (gambás), contato com animais de produção (bovinos), habitar em local sem saneamento básico e possibilidade de alagamento da região da habitação em épocas de chuva (Tabela 1).
Tabela 1 - Dados e possiveis fatores associados a infecção dos gatos positivos na

\begin{tabular}{|c|c|c|c|}
\hline \multicolumn{4}{|c|}{ Sorologia (SAM) e reação em cadeia da polimerase (PCR). } \\
\hline Sexo & Animal 1 & Animal 2 & Animal 3 \\
\hline Idade & Fêmea & Macho & Macho \\
\hline Origem & 2 anos & 8 meses & 3 anos \\
\hline SAM & $\begin{array}{c}\text { São José } \\
\text { dos Pinhais }\end{array}$ & $\begin{array}{c}\text { São José } \\
\text { dos Pinhais }\end{array}$ & Pinhais \\
\hline PCR urina & $\begin{array}{c}\text { Pomona } \\
200\end{array}$ & $\begin{array}{c}\text { Pomona } \\
400\end{array}$ & $\begin{array}{c}\text { Pomona } \\
100\end{array}$ \\
\hline Acesso à rua & Positivo & Negativo & Negativo \\
\hline Hábito de caça & Sim & Sim & Sim \\
\hline Sim & Sim & Sim \\
\hline $\begin{array}{c}\text { Contato com roedores } \\
\text { silvestres animais }\end{array}$ & $\begin{array}{c}\text { Sim } \\
\text { Sim } \\
\text { (Gambás) }\end{array}$ & São & Não \\
\hline $\begin{array}{c}\text { Contato com animais de } \\
\text { produção }\end{array}$ & $\begin{array}{c}\text { Sim } \\
\text { (Bovinos) }\end{array}$ & Não & Não \\
\hline $\begin{array}{c}\text { Coabitantes } \\
\text { Gães (7) }\end{array}$ & $\begin{array}{c}\text { Cães (9) } \\
\text { Gatos (9) }\end{array}$ & Cão (1) \\
\hline Saneamento básico na região & Não & Sim & Sim \\
\hline $\begin{array}{c}\text { Possibilidade de alagamento } \\
\text { na região }\end{array}$ & Sim & Não & Não \\
\hline
\end{tabular}

Segundo a literatura a contaminação em gatos ocorre possivelmente através da captura de roedores previamente contaminados (Hartmann et al., 2013) ou através da urina contaminada advinda de animais selvagens ou cães coabitantes (Langston \& Heuter, 2003). A infecção pode ocorrer não só pela ingestão de material contaminado, mas também através de contato com áreas lesadas da pele (Sonja et al., 2014). Os fatores associados a infecção em gatos mais comumente relatados são: hábito de caça geral, coabitantes de outro gato e acesso à rua (Bryson e Ellis, 1976; Arbour et al., 2012; Beaudu-Lange e Lange, 2014; Rodriguez et al., 2014). O ambiente parece também ter influência na infecção, esse fator é relatado para gatos que vivem em áreas inundadas (Azócar-Aedo et al., 2014), áreas com criação de bovinos (Garoussi et al., 2015) e áreas com criação de suínos (Brasil et al., 2014).

A pesquisa de anticorpos pela técnica de SAM é considerada prova padrão ouro pela Organização Mundial de Saúde, porém faz se necessária a relação desses resultados com a pesquisa de DNA bacteriano em amostras de urina, para avaliação do estado de portador renal desses animais (Greene et al., 2012; Mittestainer et al., 2015). Além disso, em cães é relatada a ocorrência de animais que apresentam leptospirúria com resultados negativos na SAM, sendo assim uma falha da 
técnica na identificação de possíveis portadores renais (Harkin et al., 2003). Em gatos isso pode ser visto também em um estudo em que 50 animais apresentaram leptospirúria na PCR, mas tinham resultados negativos na SAM (Chan et al., 2014). Desta forma foram avaliadas pela técnica de PCR todas as urinas coletadas dos 65 animais, sendo uma positiva, proveniente das coletas realizadas no município de São José dos Pinhais. Nesse caso 0 animal apresentava também sorologia positiva com título 200 para o sorovar Pomona (Tabela 1). Outros estudos também demonstraram leptospirúria em gatos e com isso os caracterizaram como reservatórios (Arbour et al., 2012; Chan et al., 2014; Fenimore et al., 2012; Rodriguez et al., 2014). Entretanto, o risco exato de contaminação de outros mamíferos, incluindo os seres humanos, a partir de gatos infectados ainda é desconhecido (Schuller et al., 2015).

A responsável pelo gato com leptospirúria negou doenças anteriores e sinais clínicos. Porém, após procedimento cirúrgico o animal apresentou quadro de desidratação e hipotermia $\left(34^{\circ} \mathrm{C}\right)$, necessitando de ressuscitação volêmica para recuperação pós-anestésica. O exame da urina, coletada antes do procedimento cirúrgico e da fluidoterapia, teve como resultados: densidade urinária 1,024, $\mathrm{pH} 8$ e sem demais alterações. Esses dados de desidratação após privação hídrica (jejum pré-cirúrgico) com baixa densidade urinária sugerem possível alteração renal, que corrobora com dados encontrados na literatura, como na compilação de três casos de leptospirose em gatos, no qual os animais apresentaram diferentes estágios de doença renal, sem nenhum sinal de doença hepática (Arbour et al., 2012). Outro estudo verificou diferença significativa entre os resultados sorológicos de um grupo de gatos com doença renal e outro considerado saudável, sugerindo que a infecção por $L$. interrogans pode ser uma causa subdiagnosticada da doença renal aguda ou crônica na espécie (Rodriguez et al., 2014).

Por muito tempo o gato não foi considerado alvo importante de controle em medidas públicas de saúde para a leptospirose, esse talvez tenha sido um ponto falho no controle da mesma e no atraso das pesquisas com esses animais. A hipótese de resistência a infecção por Leptospira spp. nessa espécie deve ser definitivamente esquecida para que se volte mais atenção ao estudo dessa enfermidade na espécie. Somente assim o papel dos gatos na epidemiologia será melhor compreendido, o que possibilitará na implantação de medidas públicas de saúde para a redução do possível risco zoonótico e melhor controle da doença na população humana e animal. Salientamos ainda a necessidade de mais estudos que elucidem a doença clínica em gatos para que medidas de prevenção e terapêutica possam ser instituídas para a espécie.

\section{CONCLUSÃO}

Gatos da região metropolitana de Curitiba/PR estão suscetíveis a infecção por Leptospira spp. e podem apresentar leptospirúria. Sendo assim, o papel de gatos como fonte de infecção ambiental ou de outros animais provavelmente está sendo subestimado. E possivelmente também o papel do agente como causador de alterações renais nessa espécie.

\section{AGRADECIMENTOS}

Ao CNPq (Conselho de Desenvolvimento Cientifico e Tecnológico) pelo apoio financeiro para a realização da pesquisa (Chamada universal $\mathrm{MCTI} / \mathrm{CNPq} \mathrm{n}^{\circ} 01 / 2016$ e 
bolsa de estudos). Ao Centro de diagnóstico Marcos Enrietti pela doação das culturas de Leptospira interrogans usadas nessa pesquisa.

\section{NOTA INFORMATIVA}

O trabalho foi aprovado pela Comissão de Ética no uso de animais (CEUA) da Universidade Federal do Paraná (UFPR), protocolo ㄲo 057/2015.

\section{REFERENCIAS}

ADLER, B.; MOCTEZUMA, A. DE LA P. Leptospira and leptospirosis. Veterinary Microbiology, v. 140, n. $3-4$, p. 287296, 2010.

AGUNLOYE, C. A.; NASH, A. S. Investigation of possible leptospiral infection in cats in Scotland. The Journal of small animal practice, v. 37, n. 3, p. 126-129, 1996.

ANDRÉ-FONTAINE, G. Canine leptospirosis - Do we have a problem? Veterinary Microbiology, v. 117, n. 1, p. 19-24, 2006.

ARBOUR, J.; BLAIS, M.-C.; CARIOTO, L.; SYLVESTRE, D. Clinical Leptospirosis in Three Cats (2001-2009). Journal of the American Animal Hospital Association, v. 48, n. 4, p. 256-260, 2012.

AZÓCAR-AEDO, L.; MONTI, G.; JARA, R. Leptospira spp. in Domestic Cats from Different Environments: Prevalence of Antibodies and Risk Factors Associated with the Seropositivity. Animals, v. 4, n. 4, p. 612-626, 2014.

BEAUDU-LANGE, C.; LANGE, E. Unusual clinical presentation of leptospirosis in a cat. Revue Vétérinaire Clinique, v. 49, n. 3, p. 115-122, 2014.

BHARTI, A. R.; NALLY, J. E.; RICALDI, J. N.; MATTHIAS, M. A.; DIAZ, M. M.; LOVETT, M. A.; LEVETT, P. N.; GILMAN, R. H.; WILLIG, M. R.; GOTUZZO, E.; VINETZ, J. M. Leptospirosis: A zoonotic disease of global importance. Lancet Infectious Diseases, v. 3, n. 12, p. 757-771, 2003.

BRASIL, A. W. DE L.; PARANTONI, R. N.; FEITOSA, T. F.; VILELA, V. L. R.; ALVES, C. J.; VASCONCELLOS, S. A.; AZEVEDO, S. S. DE. Anticorpos antiLeptospira spp. em gatos do semiárido do Estado da Paraíba. Semina: Ciências Agrárias, v. 35, n. 6, p. 32153220, 2014.

BRYSON, D.; ELLIS, W. Leptospirosis in a British domestic cat. Journal of Small Animal Practice, 1976.

CHAN, K.-W.; HSU, Y.-H.; HU, W.-L.; PAN, M.-J.; LAI, J.-M.; HUANG, K.-C.; CHOU, S.-J. Serological and PCR detection of feline leptospira in southern Taiwan. Vector borne and zoonotic diseases, v. 14, n. 1, p. 118-23, 2014.

FAINE, S.; ADLER, B.; BOLIN, C.; PEROLAT, P. Leptospira and leptospirosis. 2. ed. Melbourne, Australia: MedScience, 1999.

FENIMORE, A.; CARTER, K.; LUNN, K. $F$. Detection of Leptospiruria in Shelter cats in Colorado. Proceedings of the the 30th annual congress of the American College of Veterinary Internal Medicine - Journal of Veterinary Internal Medicine, v. 26, n. 3, p. 783, 2012.

GAROUSSI, M. T.; MEHRAVARAN, M.; ABDOLLAHPOUR, G.; KHOSHNEGAH, $J$. Seroprevalence of leptospiral infection in feline population in urban and dairy cattle herds in Mashhad, Iran. Veterinary Research Forum, v. 6, n. 4, p. 301-304, 2015.

GREENE, C. E.; SYKES, J. E.; MOORE, G. E.; GOLDSTEIN, R. E.; D., R. S. Leptospirosis. In: GREENE C. E. (Ed.). Infectious diseases of the dog and cat. 2012. ed. [s.I.] Elsevier Ltd, 2012. v. 1p. 431-447.

HARKIN, K. R.; ROSHTO, Y. M.; SULLIVAN, J. T.; PURVIS, T. J.; CHENGAPPA, M. M. Comparison of 
polymerase chain reaction assay, bacteriologic culture, and serologic testing in assessment of prevalence of urinary shedding of leptospires in dogs. Journal of the American Veterinary Medical Association, v. 222, n. 9, p. 1230-1233, maio 2003.

HARTMANN, K. et al. Leptospira species infection in cats: $A B C D$ guidelines on prevention and management. Journal of feline medicine and surgery, v. 15, p. 576-81, 2013.

JAMSHIDI, S.; AKHAVIZADEGAN, M.; BOKAIE, S.; MAAZI, N.; GHORBAN ALI, A. Serologic study of feline leptospirosis in Tehran, Iran. Iranian Journal of Microbiology, v. 1, n. 2, p. 32-36, 2009. LANGSTON, C. E.; HEUTER, K. J. Leptospirosis. A re-emerging zoonotic disease. Veterinary Clinics of North America - Small Animal Practice, v. 33, n. 4, p. 791-807, 2003.

LAPOINTE, C.; PLAMONDON, I.; DUNN, $M$. Feline leptospirosis serosurvey from a Quebec referral hospital. Canadian Veterinary Journal, v. 54, n. 5, p. 497499, 2013.

LÉVESQUE, B.; SERRES, G.; HIGGINS, R.; D'HALEWYN, M.-A.; ARTSOB, H.; GRONDIN, J.; AL., E. Seroepidemiologic study of three zoonoses (leptospirosis, $Q$ fever, and tularemia) among trappers in Québec, Canada. Clinical and diagnostic laboratory imunology, v. 2, n. 4, p. 496-498, 1995.

LUCCHESI, P. M. A; ARROYO, G. H.; ETCHEVERRÍA, A. I.; PARMA, A. E.; SEIJO, A. C. Recommendations for the detection of Leptospira in urine by PCR.

Revista da Sociedade Brasileira de Medicina Tropical, v. 37, n. 2, p. 131134, 2004.

MARKOVICH, J. E.; ROSS, L.; MCCOBB, E. The prevalence of leptospiral antibodiesin free roaming cats in worcester country, Massachusetts.
Journal of Veterinary Internal

Medicine, v. 26, n. 2, p. 688-689, 2012.

MILLÁN, J.; CANDELA, M. G.; LÓPEZBAO, J. V.; PEREIRA, M.; JIMÉNEZ, M. A.; LEÓN-VIZCAÍNO, L. Leptospirosis in wild and domestic carnivores in natural areas in Andalusia, Spain. Vector borne and zoonotic diseases, v. 9, n. 5, p. 549-554, 2009.

MITTESTAINER, J. C.; MELCHERT, A.; RIBEIRO, J. F. A.; SARTORI, R. S.; JOAQUIM, S. F.; BRESCIANI, K.; LANGONI, H. Estudo soroepidemiológico da infecção por Leptospira spp. em gatos. Revista Veterinária e Zootecnica - Faculdade de Medicina Veterinária e Zootecnia-UNESP, v. 22, n. 3, p. 465470, 2015.

POL, M. VAN DE. Leptospirosis in wildlife and cats - Pilot study. [s.l.] UTRECHT UNIVERSITY, 2016.

RODRIGUEZ, J.; BLAIS, M. C.; LAPOINTE, C.; ARSENAULT, J.; CARIOTO, L.; HAREL, J. Serologic and urinary PCR survey of leptospirosis in healthy cats and in cats with kidney disease. Journal of Veterinary Internal Medicine, v. 28, n. 2, p. 284-293, 2014.

SCHULLER, S.; FRANCEY, T.; HARTMANN, K.; HUGONNARD, M.; KOHN, B.; NALLY, J. E.; SYKES, J. European consensus statement on leptospirosis in dogs and cats. Journal of Small Animal Practice, v. 56, n. 3, p. 159-179, 2015.

SHOPHET, R.; MARSHALL, R. B. An experimentally induced predator chain transmission of Leptospira ballum from mice to cats. British Veterinary Journal, v. 3, p. 265-270, 1980.

SONJA, O.; SONJA, R.; NATAŠA, S.; DANICA, B.; SLOBODANKA, V.; MIROSLAV, V. Seroprevalence of Cat Leptospirosis in Belgrade (Serbia). Acta Veterinaria, v. 64 , n. 4, p. 510-518, 2014. 